\title{
DEVELOPMENT OF A GRAPHICAL USER INTERFACE AND GRAPHICS DISPLAY FOR THE WIND SYSTEM (U)
}

WSRC-RP--92-1425

by

DE93 011780

B. L. O'Steen

Savannah River Site

Aiken, South Carolina 29808

J. D. Fast

(WSRC)

B. S. Suire

(WSRC)

A document prepared for:

at

from thru

This paper was prepared in connection with work done under the above contract number with the U.S.

Department of Energy. By acceptance of this paper, the publisher and/or recipient acknowledges the U.S.

Governiment's right to retain a nonexclusive, royalty-free license in and to any copyright covering this paper, along with the right to reproduce and to authorize others to reproduce all or part of the copyrighted paper. 


\section{DISCLAIMER}

This report was prepared as an account of work sponsored by an agency of the United States Government. Neither the United States Government nor any agency thereof, nor any of their employees, makes any warranty, express or implied, or assumes any legal liability or responsibility for the accuracy, completeness, or usefulness of any information, apparatus, procuct, or process disclosed, or represents that its use would not infringe privately owned rights. Reference herein to any specific commercial product, process, or service by trade name, trademark, manufacturer, or otherwise does not necessarily constitute or imply its endorsement, recommendation, or favoring by the United States Government or any agency thereof. The views and opinions of authors expressed herein do not necessarily state or reflect those of the United States Government or any agency thereof.

This report has been reproduced directly from the best available copy.

Available to DOE and DOE contractors from the Office of Scientific and Technical Information, P.O. Box 62, Oak Ridge, TN 37831; prices available from (615) 576-8401, FTS 626-8401.

Available to the public from the National Technical Information Service, U.S. Department of Commerce, 5285 Port Royal Rd., Springfield, VA 22161. 


\title{
Development of a Graphical User Interface and Graphics Display for the WIND System
}

\author{
by B.L. O'Steen, J.D. Fast and B.S. Suire \\ Westinghouse Savannah River Company \\ Savannah River Technology Center \\ Environmental Technology Section
}

S u m m a r y

An advanced graphical user interface (GUI) and improved graphics for transport calculations have been developed for the Weather Information and Display System (WINDS). Two WINDS transport codes, Area Evac and 2DPUF, have been ported from their original VAX/VMS environment to a UNIX operating system and reconfigured to take advantage of the new graphics capability. A developmental prototype of this software is now available on a UNIX based IBM 340 workstation in the Dose Assessment Center (DAC). Automatic transfer of meteorological data from the WINDS VAX computers to the IBM workstation in the DAC has been implemented. This includes both regional National Weather Service (NWS) data and SRS tower data. The above developments fulfill a FY 1993 DOE milestone.

Future plans include the porting and reconfiguration of all remaining WINDS transport codes and implementation of the fully revamped WIND system in both the DAC and area control rooms. A set of Geographical Information System (GIS) functions and companion GUI accessed from the WINDS GUI has also been developed and awaits implementation. Full quality assurance, documentation and training on the new GUI are not included in this phase of the project. Therefore, this software should not be considered operational at this time. 


\section{Introduction}

In FY 1992, the Environmental Transport Group began the development of a new user interface for the WIND system and a new graphics display for WINDS transport model results. This project was designed to: (1) provide a better user interface for accessing WINDS codes and entering data (2) produce better output graphics (3) begin the migration of WIND system applications to UNIXbased workstations. The first goal was accomplished by the creation of a Motifbased graphical user interface (GUI). A riew graphics package was then developed, and integrated with the GUI, to produce a more complete and understandable presentation of model results. The new graphics dispiay also includes a set of GIS applications and a separate GUI for these applications; however, implementation of the GIS package is not complete. When fully implemented, access to the GIS package will be through the WIND system GUI. All of the above software was developed for UNIX-based workstations. Moving WINDS application codes to these workstations was an integral part of the development plan. The workstations are faster than the WIND system VAX 8550 computers and much more cost efficient. Collecting and archiving meteorological and radiological monitor data will remain a task for the VAX computers, while the workstations perform the more computationally intensive jobs. The transition to a UNIX operating system was undertaken to provide a more conducive environment for integrating Emergency Management Division computer systems with the WIND system.

In the initial phase of this project, the WIND system GUI and graphics package were created and two WINDS codes (2DPUF, Area Evac) ported to the UNIX. operating system These codes were reconfigured to produce data files for the new graphics package. A single workstation in the DAC was linked to the WINDS network, and automatic, real-time transfer of meteorological data implemented using the File Transfer Protocol (FTP) utility within TCP/IP. This workstation provides the initial test platform for the revamped WIND system. Later, workstations will be installed in the area control rooms where results from Area Evac can be displayed over the appropriate area map. This display will be updated every 15 minutes based on the latest meteorological data from the local area tower.

A prototype of the above software, with Area Evac and 2DPUF as example applications, is now available on an IBM workstation in the DAC. The installation and demonstration of this software on the DAC workstation was designated a DOE milestone in July of 1992. This milestone has now been met. A discussion of the GUI and new graphics capabilities follows.

\section{Graphical User Interface}

The current WIND system user interface is based on a Fortran coded "questionand-answer" format. This type of interface is used for both application selection (main menu) and data input to transport models. The main problem with this interface is the inability to easily view and alter input data once the data has been specified. The Motif based GUI developed for the WIND system completely eliminates this problem. All information is entered through Motif selection boxes which are organized in a logical manner on the workstation monitor. Application selection and data input are always displayed and can be changed at any time prior to code execution. The primary GUI display is shown in Figure 1. 
The main option is its automatic/interactive selection in the upper left hand corner of Figure 1. In the interactive mode (shown in Fig. 1), the user has direct access to the entire WIND system. Major interactive options are located at the top of the graphics display. Only the button for selecting a transport model is currently operational. The source model button is inactive. As source models and default lists become available, they will be accessed under this option to provide a source input for a subsequent transport model run. The GIS and the monitor display software have been developed, but are not linked to the new WIND system GUl. This linkage will occur during the implementation phase of the project. Immediately below the interactive option bar is a display of the current meteorological conditions (updated every 15 minutes). Below this is the primary graphics display for the background maps and the plume. The type of information presented in the graphics display is controlled by the data class selection box in the lower left corner of the monitor screen. Three classes are identified: model output, meteorology, and background maps. When one of these data classes is selected, a listing of data types for display is presented in the selection box immediately to the right of the data class box. Map types include detailed area maps, detailed site map and a regional map. Roads, rivers/lakes, city/political boundaries, railroads and the site boundary are included in these maps. Maps of population distributions (by age), landuse and rainfall (radar) can be displayed via the GIS utilities (when operational). Meteorology data includes SRS tower data, NWS surface observations, NWS upper-air soundings and the MOS forecast. Model output includes various types of dose calculations, dose rate, concentration and deposition.

Once the transport model option has been been selected, a list of available transport codes appears. After selecting a code to run, a data input screen is displayed. All relevant model input data is entered and displayed through this screen and its daughters; these daughters include a manual meteorology input screen and a source input screen. Changes can be made at any time prior to code execution or the entire input can be canceled. The transport code is executed by selecting the run option on the input screen. Input screens for 2DPUF and Area Evac are shown in Figures 2 and 3.

The automatic mode is designed to continuously produce a default plume display based on the current meteorology. Results are updated every 15 minutes as new meteorological data becomes available. A default source strength is used and a shaded plume indicates the affected area. The screen for this option is shown in Figure 4. The background map, iransport code, source location and meteorology used in the automatic mode depend on the area of interest. This mode is primarily intended for workstations located in area control rooms. In this case, the map would be the appropriate area map, the transport code would be Area Evac and meteorology from the local area tower would be utilized for transport calculations. Current meteorological conditions are shown at the top of the graphics display. Rally points outside of the plume are listed to the left of the graphics display. In the DAC, the automatic mode would typically be run with a SRS background map using 2DPUF as the transport code. Site averaged meteorology (SAM) would be used for transport calculations with the source location at the site center. 


\section{Graphics Display}

The results of the model run can be displayed by selecting model output in the data class selection box and choosing a variable from the subsequent data type list. Once a variable is chosen, contours for that variable will be displayed in the graphics window. Any combination of background maps can be displayed with the model results by selecting maps from the data class box and choosing maps from the data type box. A regional map is shown in Figure 5 and a higher resolution map surrounding $S R S$ in Figure 6. General information related to the model run is shown to the left of the graphics display. This includes the time of the model results currently displayed and a legend defining the contour levels. Four colors are provided for shading contour levels. If the data type is a dose, then the color shading will correspond to specific PAGs or EALs. Data values outside of the "color" levels are contoured with labeled white lines. The new graphics package allows one to monitor the progression of the plume in time. The display speed is controlled by the "VCR" buttons at the bottom of the graphics display. Depressing the " $>$ " button advances the plume one frame at a time (typically 30 or 60 minutes), while the " $>$ " button produces an animation or fast-forward mode. The solid button stops the animation. Immediatcly to the right of the "VCR" controls is a slider for zoom control. A graphics toolkit is also provided in the bottom right corner of the monitor screen. The centering tool allows one to move the displayed image; this is normally used when zooming in on a small area of the display. The road block, monitor van and TRAC vehicle are locatable icons; they can be "dragged" to any point on the display. This provides a simple and quick method to track the location of access control points and monitoring teams. The time-series tool produces a plot of the current data type versus time at any point in the graphics display. An example time-series plot is shown in Figure 7. This tool is activated by simply "dragging" the time-series icon to a location within the graphics window. A quick determination of "time-of-arrival" can be made with the aid of this tool. Finally, there is a tool (plume shaped icon) which can be used to quickly move the source location.

\section{Future Plans}

The ultimate goal of this project is to completely replace the current WIND system with the software described above. To accomplish this the following tasks must be completed:

- The GIS and Monitor options must be implemented within the GUI

- The remaining WINDS codes must be ported to the workstations and reconfigured to produce the appropriate output files

- Workstations must be installed in the area control rooms

- The site network must be extended to the area rooms and the workstations added to the network

- The new WIND system must be quality assured

- Training and documentation for the new WIND system must be provided 


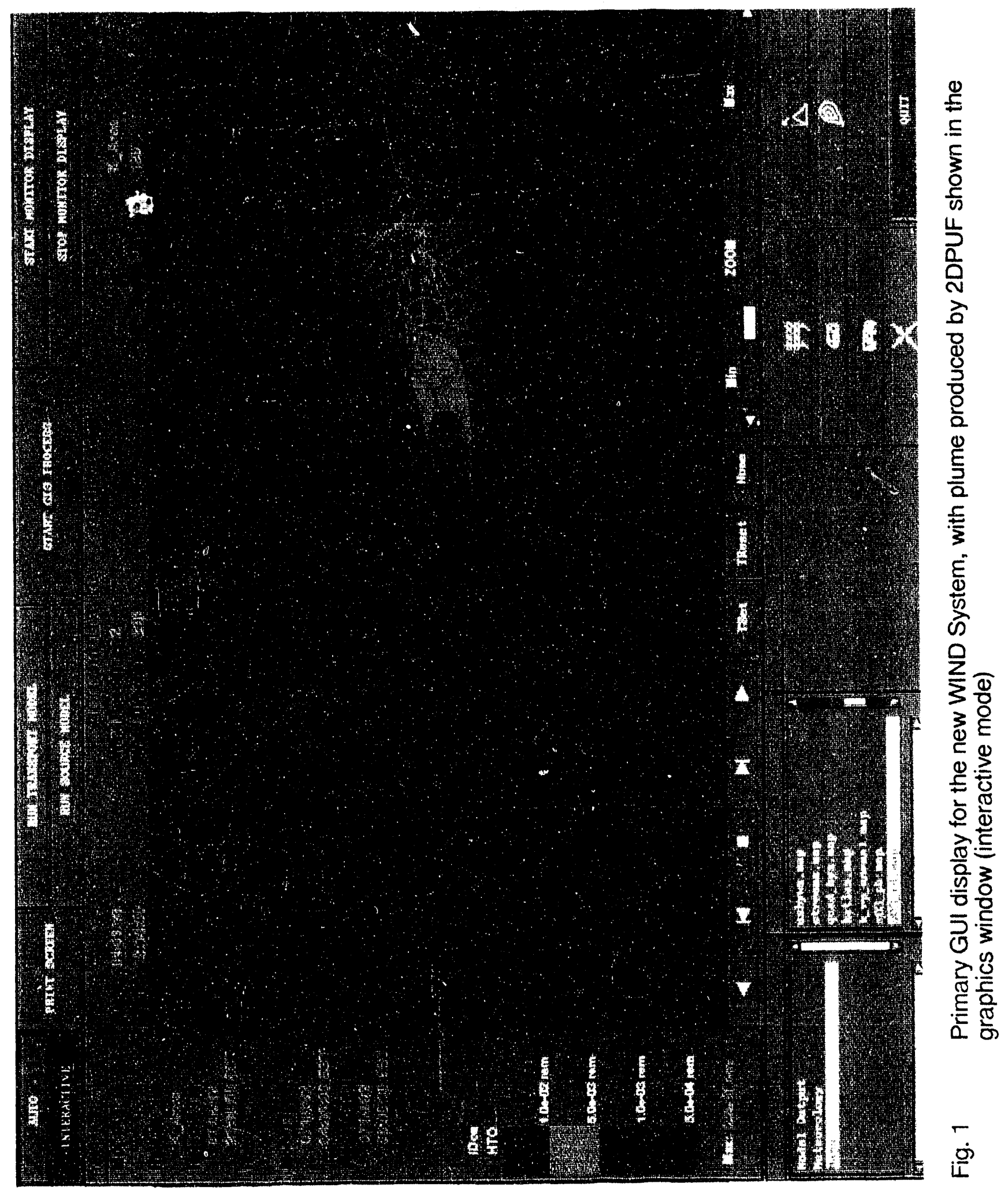




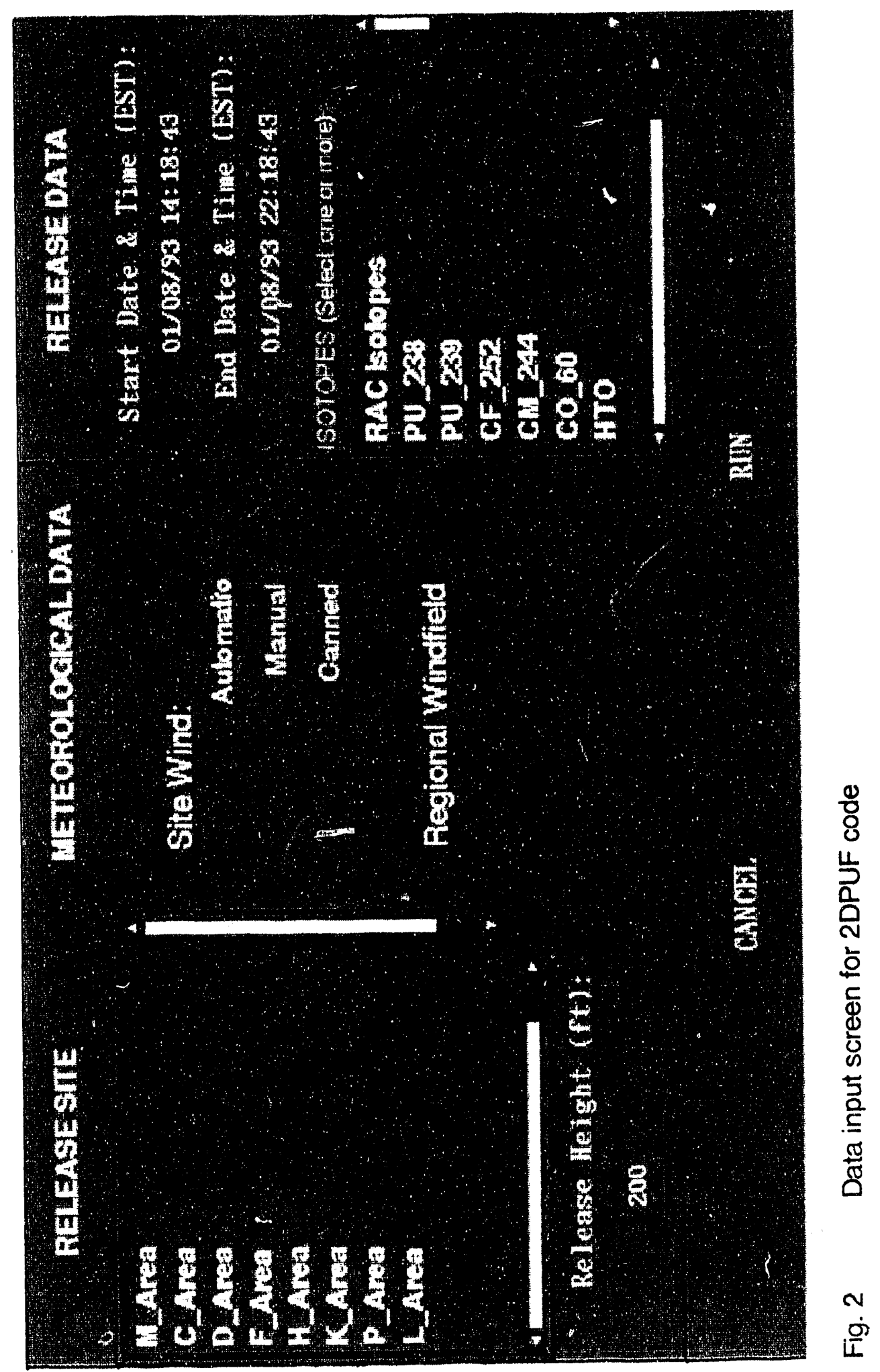




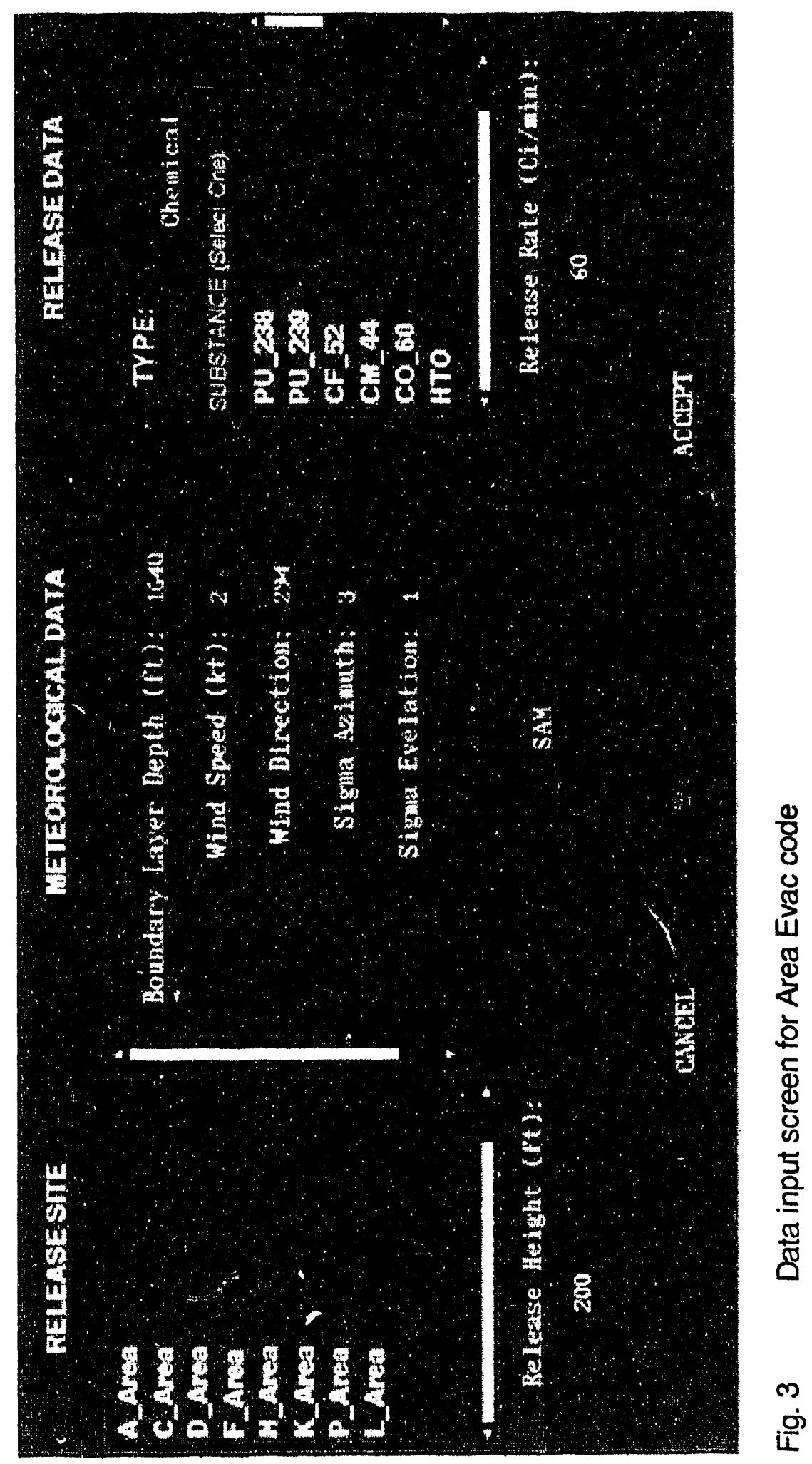




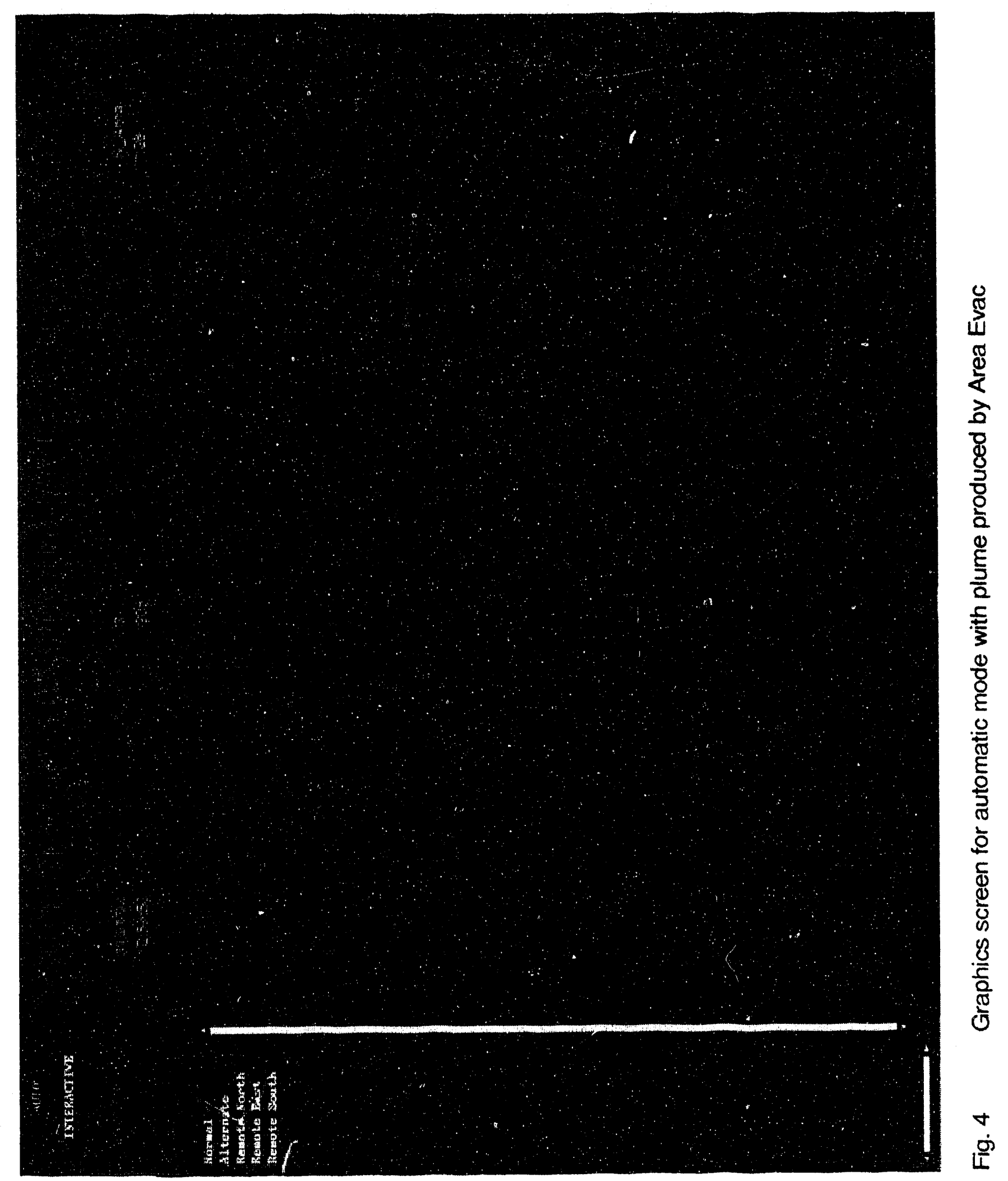




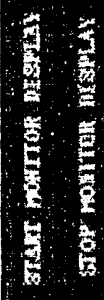

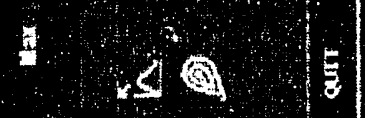

a $8 x$

s)

8

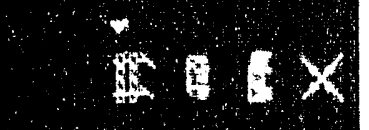

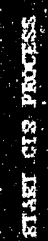

1

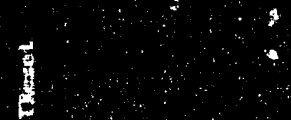

点

$\frac{9}{8}$
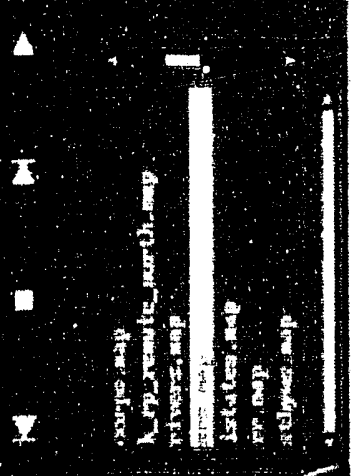

$\frac{8}{5}$

8

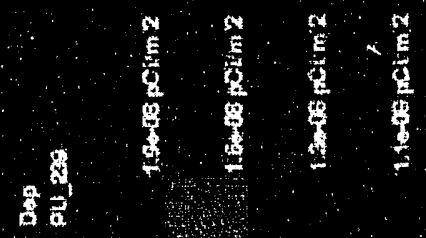

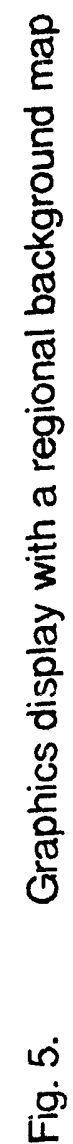




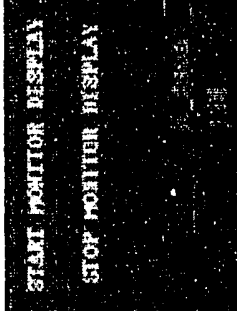

है

$\frac{8}{8}$

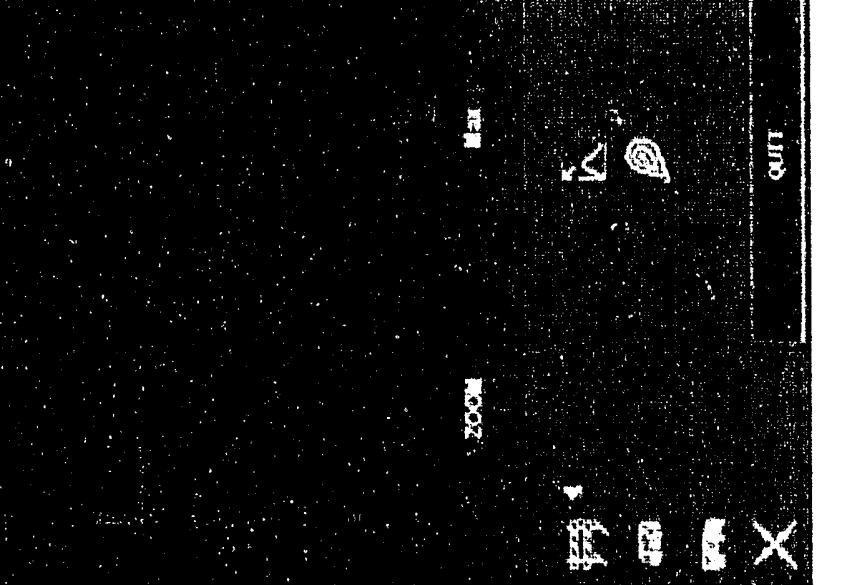

s]

I

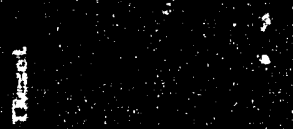

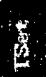

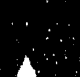

$\Delta,-., \frac{8}{8}$

$\tau$,

41

- I $f . \mathrm{C}^{\mathrm{F}}$

7)

x SHEt $\frac{\pi}{2}$

-

$7 \quad 1$

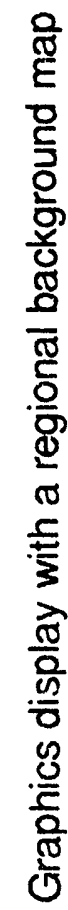

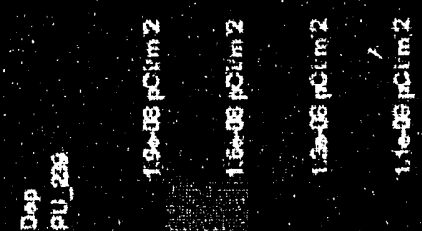

is 


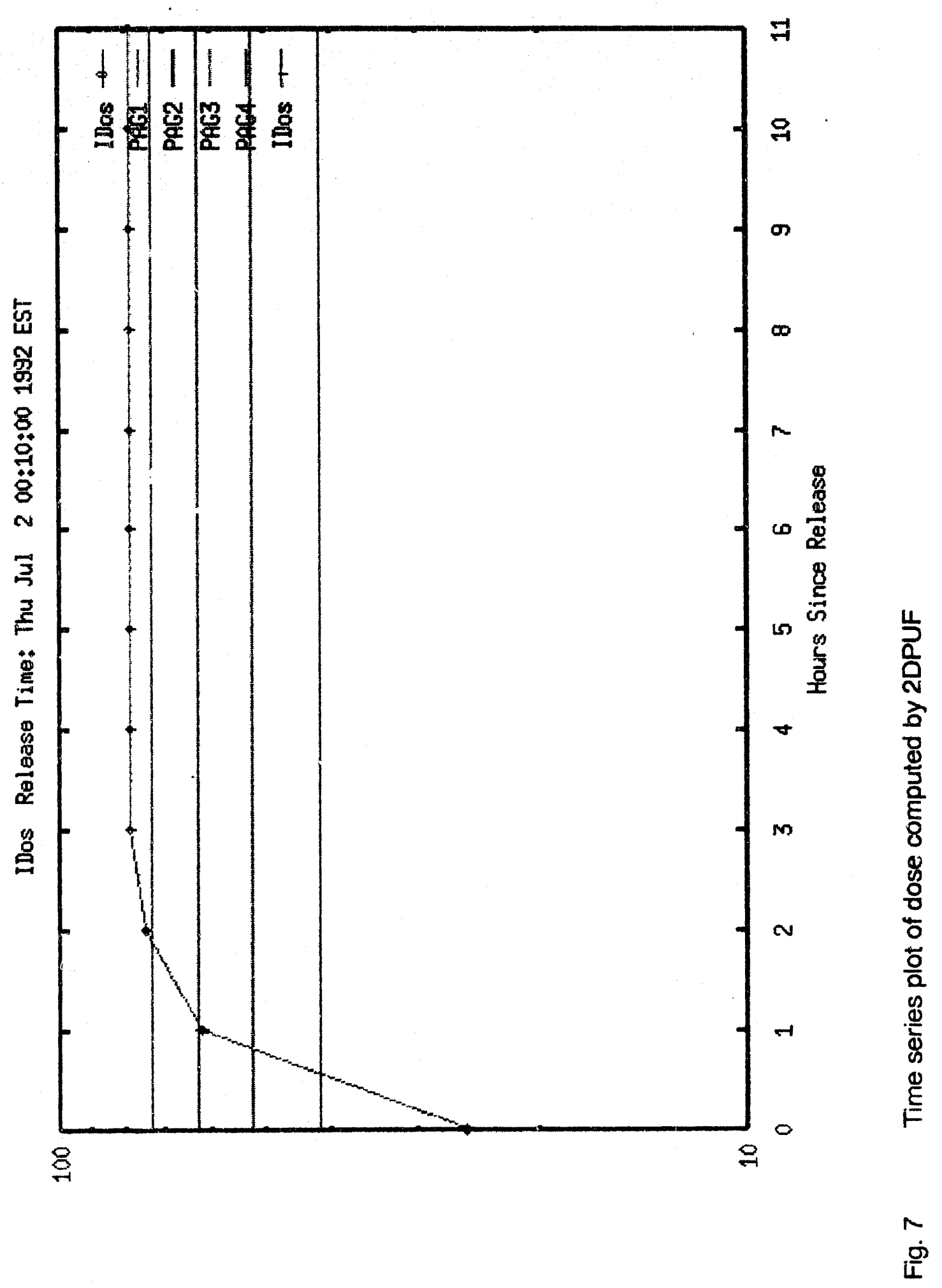



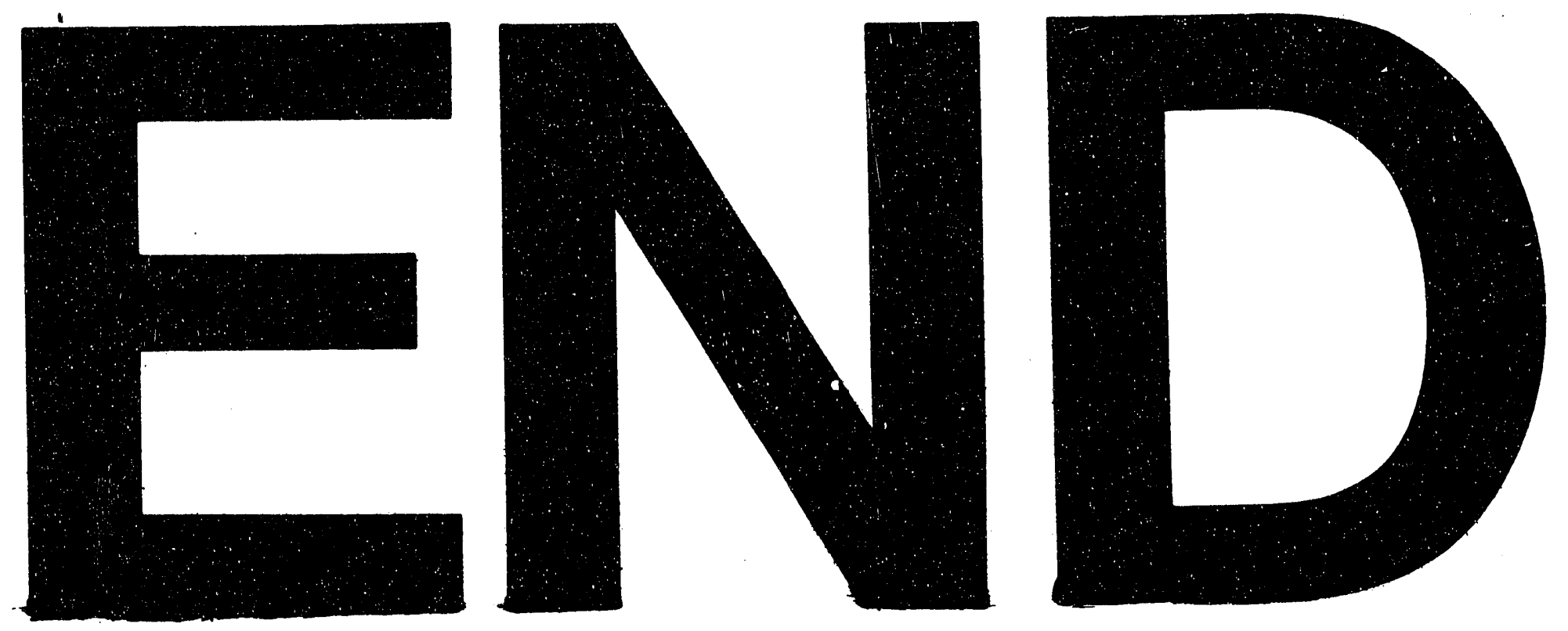

$\therefore$

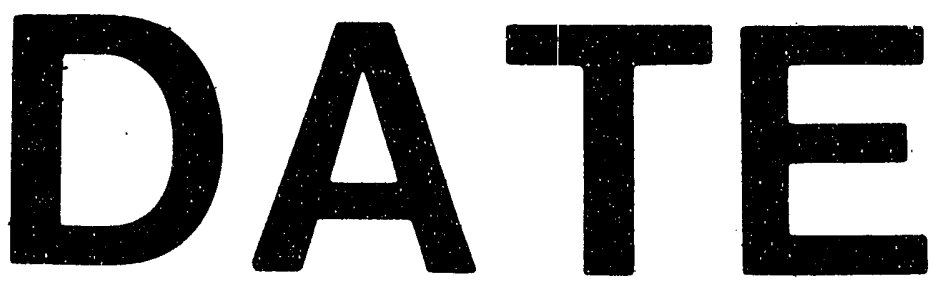

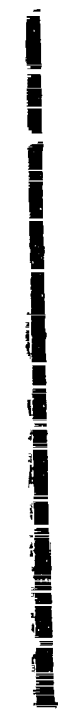
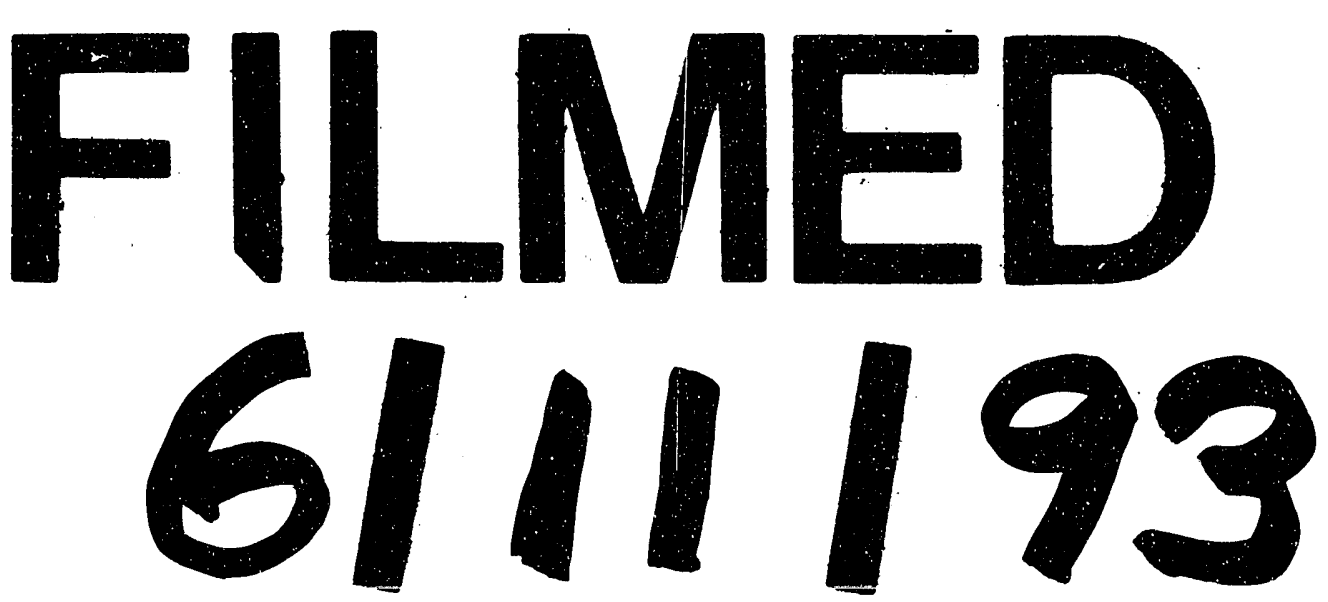
